\title{
Change of Physical and Water-Physical Properties of the Reclamation Pratal Saline Lands of Submountain Plains of Ili Alatau
}

\author{
PhD students Aigul Beketova, Zhainagul Ertayeva and Prof. Saginbay Kaldybayev ${ }^{1}$
}

\begin{abstract}
The resalinization of irrigable earth brings an enormous damage to agriculture. Worsening of the water-salt mode of soil results to the decline of the productivity of irrigable earth and fall of part of irrigable plough-land from an agricultural turn. Researches were conducted on the before reclamated pratal saline lands in the natural conditions and under the lucerne (in the submountain plains of Ili Alatau, in the farm of Teskensu, of the Almaty region). Were investigated such parameters as volume weight, unit weight, porosity of soils, maximal hygroscopicity, wilting moisture, the minimum moisture-capacity.
\end{abstract}

Keywords - the reclamated pratal saline land, volume mass, porosity of soils, maximal hygroscopicity.

\section{INTRODUCTION}

A LMOST all territory of Republic of Kazakhstan belongs to the internal-drainage area of dry land, where because of its physic-geographic features the large areas of salt soils of the CIS are concentrated and it is one of the saltiest parts of Central Asia. This territory in all geological epochs was the zone of intensive salt reserve (at the average 1,6 tons $/ \mathrm{km}^{2}$ per year) and its modern level (20-40 tons $/ \mathrm{km}^{2}$ per year) is one of the highest one [1].

The resalinization of irrigable earth brings an enormous damage to agriculture. Principal reason of this harmful phenomenon is an absence of engineering collector-drainage network in the conditions of weak natural outflow of subsoil waters. Worsening of the water-salt mode of soil results to the decline of the productivity of irrigable earth and fall of part of irrigable plough-land from an agricultural turn.

\section{MATERIALS AND METHODS}

As we know, physical and water properties of soils, being the function of past processes of soil formation, by turn makes big influence on its direction and rate of further soil formation process. The use of this position allows to estimate correctly the genetic features of soils and on their basis to work out most acceptable agrotechnical and reclamative measures for optimization their fertility $[2,3]$.

Therefore the study of physical and water properties of the investigated soils gives an opportunity to define their changes and efficiency during land-reclamation.

Researches were conducted on the before reclamated pratal saline lands in the natural conditions and under the lucerne (in the submountain plains of Ili Alatau, in the farm of Teskensu, of the Almaty region). Were investigated such parameters as volume weight, unit weight, porosity of soils, maximal hygroscopicity, wilting moisture, the minimum moisturecapacity.

\section{THE RESULTS OF RESEARCHES AND DISCUSSION}

The volume weight. A density of constitution of soil is very dynamic property in superficial horizons of soil and is in difficult dependence on mechanical composition, structural state, maintenance of organic substance, easily soluble salts, root-inhabited systems of plants. It suffers a considerable change at irrigation and especially by mechanic tooling of soils.

It was determined by data of scientists, that optimal for development of cultural plants is a density of arable layer within the limits of $1,10-1,35 \mathrm{~g} / \mathrm{cm}^{3}$. At the density of constitution of soil under below or higher than this limit the water-air, thermal and food modes of soils get worse, the growth, development of plants and harvest of agricultural cultures go down.

As the data of the investigated soils showed, before washing of the lowest quantity of volume weight was characterized at the top horizon $0-40 \mathrm{~cm}(1,19-1,26)$, where the maximal amount of salts and organic substances are concentrated. Here the sodium sulfate prevails in the content of salts, and, as is generally known, it is characterized with middle solubility, hygroscopicity and is found in such two forms as mirabilite $\mathrm{Na}_{2} \mathrm{SO}_{4} * 10 \mathrm{H}_{2} \mathrm{O}$ and thenardite $\mathrm{Na}_{2} \mathrm{SO}_{4} * \mathrm{H}_{2} \mathrm{O}$. The mellowing on soil mass has influence on the transition of them from one form to another.

Downward on the profile of soil - deeper at $40 \mathrm{~cm}$ happened sharp increase of volume weight to $1,62 \mathrm{~g} / \mathrm{cm}^{3}$ and its composition by the Kachinskiy scale estimated as strongly compressed [4].

The capital washing, rendering the saline operating on the zone of aeration of soils and lands, causes the change of quantitative and quality composition of salts, and consequently to the volume weight of soils on all profile [5]. Compression of overhead horizons of soils, as a result, of its salinization made it possible to explain the shrinkage of soils, related to alteration of soil mass.

\footnotetext{
${ }^{1}$ Kazakh National Agrarian University, Almaty, Kazakhstan
} 
TABLE I. Change of volume weight of the pratal saline lands under the post reclamation methods, $\mathrm{g} / \mathrm{cm}^{3}$

\begin{tabular}{|c|c|c|c|c|c|}
\hline \multirow{2}{*}{$\begin{array}{c}\text { Depth, } \\
\mathrm{cm}\end{array}$} & $\begin{array}{c}\text { Before } \\
\text { washing } \\
(1986)\end{array}$ & $\begin{array}{c}\text { After } \\
\text { washing } \\
(1987)\end{array}$ & \multicolumn{2}{|c|}{$\begin{array}{c}\text { After the three years of } \\
\text { cultivation of lucerne } \\
(1989)\end{array}$} & $\begin{array}{c}\text { The post } \\
\text { reclamatio } \\
\text { n period } \\
(2015)\end{array}$ \\
\cline { 4 - 5 } & & $\begin{array}{c}75 \% \\
\text { from } \\
\text { MMC }\end{array}$ & $\begin{array}{c}85 \% \text { from } \\
\text { MMC }\end{array}$ & \\
\hline $0-20$ & 1,19 & 1,35 & 1,36 & 1,31 & 1,39 \\
\hline $20-40$ & 1,26 & 1,39 & 1,38 & 1,35 & 1,40 \\
\hline $40-60$ & 1,53 & 1,47 & 1,42 & 1,43 & 1,44 \\
\hline $60-80$ & 1,56 & 1,53 & 1,50 & 1,49 & 1,50 \\
\hline $80-100$ & 1,60 & 1,58 & 1,56 & 1,53 & 1,52 \\
\hline
\end{tabular}

The cultivation of lucerne, on the preliminary desalinated soils, in three years, with the mode of irrigation $75 \%$ from MMC, did not have influence on the quantity of volume weight. And on the variant of $85 \%$ from MMC, where the higher washing water mode was supported, this index went down to $1,31-1,35 \mathrm{~g} / \mathrm{cm}^{3}$. The decline of volume weight happened in lower horizons too, as compared with the initial state.

The substantial change of density of addition of pratal saline lands happened, as a result, of the capital washing and cultivation on the desalinated soil of culture of lucerne. Structureless mellow soil in overhead $0-40 \mathrm{~cm}$ layer, and strongly compressed below $40 \mathrm{~cm}$ layer soil purchased a normal structure and good enough constitution.

After the continuous post-reclamative period (2015), in the conditions of the productive sowing some compressions of overhead horizons were occurred. The volume weight in a layer $0-100 \mathrm{~cm}$ was $1,39-1,52 \mathrm{~g} / \mathrm{cm}^{3}$.

The unit weight._Unit weight of hard phase of soils, as is generally known, depends on mineralogical composition, maintenance in it of organic substance and salts. As the data of table 2 shows, unit weight of hard phase of overhead horizons of pratal saline lands before washing (1986) was 2,63-2,66, with an increase the depth to $2,70-2,75 \mathrm{~g} / \mathrm{cm}^{3}$.

TABLE 2. Change of unit weight of the pratal saline lands under the reclamation methods, $\mathrm{g} / \mathrm{cm}^{3}$.

\begin{tabular}{|c|c|c|cc|c|}
\hline $\begin{array}{c}\text { Depth, } \\
\mathrm{cm}\end{array}$ & $\begin{array}{c}\text { Before } \\
\text { washing } \\
(1986)\end{array}$ & $\begin{array}{c}\text { After } \\
\text { washing } \\
(1987)\end{array}$ & $\begin{array}{c}\text { After the three years of } \\
\text { cultivation of lucerne } \\
(1989)\end{array}$ & $\begin{array}{c}\text { The post } \\
\text { reclamation } \\
\text { period (2015) }\end{array}$ \\
\cline { 4 - 5 } & & & $\begin{array}{c}75 \% \text { from } \\
\text { MMC } \begin{array}{c}85 \% \\
\text { from } \\
\text { MMC }\end{array}\end{array}$ \\
\hline $0-20$ & 2,63 & 2,69 & 2,69 & 2,59 & 2,61 \\
\hline $20-40$ & 2,66 & 2,71 & 2,72 & 2,61 & 2,66 \\
\hline $40-60$ & 2,70 & 2,72 & 2,73 & 2,68 & 2,70 \\
\hline $60-80$ & 2,75 & 2,73 & 2,71 & 2,71 & 2,72 \\
\hline $80-100$ & 2,72 & 2,73 & 2,71 & 2,73 & 2,74 \\
\hline
\end{tabular}

Under influence of washings and tilled lucerne there is change: after washing the increase is marked in overhead horizons $(2,69-2,71 \mathrm{~g} / \mathrm{of} \mathrm{cm} 3)$, that, maybe, it is related to making of mechanical composition and compression of profile of soil heavier after washing.
In a cultivation period (under the lucerne of the $3^{\text {rd }}$ of life) in overhead horizons (on a variant $85 \%$ MMC) there is reduction of unit weight of soil to $2,59-2,61 \mathrm{~g} / \mathrm{cm}^{3}$.

Some reduction of unit weight after realization of washings takes place in a cultivation period under an lucerne and mainly in overhead, more humus horizons due to the increase of the yellowed bits and pieces and root mass of lucerne.

Determination of unit weight of soil after the continuous post-reclamative period showed, that its further reduction is in a layer $0-40 \mathrm{~cm}$ to $2,57-2,59 \mathrm{~g} / \mathrm{cm}^{3}$. Apparently, it is explained by the increase of amount of organic substances (humus - 2,98 $\%)$ and yellowed bits and pieces of agricultural cultures.

Porosity of soils._Porosity determines many properties of soil such as moisture-capacity, capillary getting up and evaporation of moisture, motion of moisture, nourishing elements and salts in soil, availability of moisture to the plants, maintenance of air in soil, effective volume of development of rootage of plants and vital functions of microorganisms.

The detailed study of porosity of different types of soils is conducted by N. Kachinskiy, M. Polskiy; A. Doyarenko, A. Rode, A. Sukhachev, D. Manukyan and etc. [4, 6, 7].

According to the quantity of volume weight and unit weight the total porosity of soil before washing (1986) in a layer 0-40 $\mathrm{cm}$ was $54,8-52,6 \%$ (table 3 ), in low layers it goes down to $43,4-41,2 \%$ and estimated as unsatisfactory.

TABLE 3. Change of total porosity of the pratal saline lands under the reclamation methods, $\mathrm{g} / \mathrm{cm}^{3}$.

\begin{tabular}{|c|l|c|c|c|c|}
\hline \begin{tabular}{|} 
Depth, \\
$\mathrm{cm}$
\end{tabular} & $\begin{array}{l}\text { Before } \\
\text { washing } \\
(1986)\end{array}$ & $\begin{array}{l}\text { After } \\
\text { washing } \\
(1987)\end{array}$ & $\begin{array}{l}\text { After the three years of } \\
\text { cultivation of } \\
\text { (1989) }\end{array}$ & $\begin{array}{l}\text { The post } \\
\text { lucerne } \\
\text { reclamatio } \\
\text { period } \\
\text { (2015) }\end{array}$ \\
\cline { 4 - 6 } & & $\begin{array}{l}75 \% \text { from } \\
\text { MMC }\end{array}$ & $\begin{array}{l}85 \% \\
\text { from } \\
\text { MMC }\end{array}$ & \\
\hline $0-20$ & 54,8 & 49,8 & 49,5 & 49,6 & 46,7 \\
\hline $20-40$ & 52,6 & 48,7 & 49,3 & 48,3 & 47,3 \\
\hline $40-60$ & 43,4 & 46,0 & 48,0 & 46,7 & 46,6 \\
\hline $60-80$ & 43,3 & 44,0 & 44,7 & 45,1 & 44,8 \\
\hline $80-100$ & 41,2 & 42,2 & 42,5 & 44,0 & 44,5 \\
\hline
\end{tabular}

After realization of washings and cultivation of lucerne - in cultivation period (1989), and also after the continuous postreclamative period (2015) in the conditions of the productive sowing of agricultural cultures there is some decline of total porosity in a meter layer $-47,3-44,5 \%$, that correlates with the increase of by volume weight of soil.

Maximal hygroscopicity $(M H)$. Soil moisture in a state of maximal hygroscopicity is firmly constrained and it moves as steam, and that is why does not dissolve salt, quite inaccessible to the plants and is a "dead supply".

The quantity of $\mathrm{MH}$ in a soil profile before washing (1986) fluctuated within the limits of 7,25-4,96\%. Some increase of $\mathrm{MH}$ in overhead horizons as compared with low layers is explained by higher maintenance in soil of humus and watersoluble salts. Stocked moisture, corresponding $\mathrm{MH}$, before washing in a meter layer was $838,3 \mathrm{~m}^{3} / \mathrm{ha}$, after washing (1987) its size was $6,37-4,73 \%$, with the supply of moisture in the meter layer of $785,2 \mathrm{~m}^{3} / \mathrm{ha}$. It is necessary to suppose washing reduces a value $\mathrm{MH}$ of soils, because of washing easily soluble hygroscopic salts. So, according to data of M.Umarov [8], increasing of degree of salinization to 1 and 
more percentage on a dense remain increases $\mathrm{MH}$ in 2 times against its indexes in the soils washed from salts.

In a cultivation period - under the lucerne of $3^{\text {rd }}$ of life there is some reduction of quantity of $\mathrm{MH}$, thus on a variant $85 \%$ from MMC is more noticeable, than on a variant $75 \%$ from MMC (in a layer 0-20 cm - 5,20 and 5,65\%, respectively), and in a post-reclamative period - 5,01

Quite inaccessible for plants supply of moisture, i.e. its dead supply, in the meter layer of soil was 646,5 and $709,5 \mathrm{~m}^{3} / \mathrm{ha}$, and after the continuous post-reclamative period - 641,10 $\mathrm{m}^{3} /$ ha.

Wilting moisture (WM). Wilting moisture of plants depends on genetic properties of soils, type of plants and phases of their development. On availability for plants, soil moisture of category of WM behaves to difficult of access, that is composed from maximal maintenance of firmly linked and partly mellow constrained moisture [9].

A quantity of WM is a border between accessible and inaccessible for plants soil moisture. At reduction of soil moisture to the quantity of WM the physiological and biochemical processes of plants are broken, their height stops, wilting and even death comes.

Before washing (1986) the quantity of WM of plants in a meter layer fluctuated within the limits of $9,71-6,64 \%$, that corresponds to the supply of inaccessible for plants moisture as $1141,8 \mathrm{~m}^{3} /$ ha.

After washing (1987) the index of WM went down a little bit till 8,53-6,34\% in an overhead meter layer, that in a count on a supply is equal to $1051,7 \mathrm{~m}^{3} /$ ha. Under the lucerne of $3^{\text {rd }}$ of cultivation (1989) the quantity of WM of plants in connection with some salinization of soil profile notably went down and in the overhead meter layer fluctuated on a variant of $75 \%$ from MMC within the limits of 7,57-5,96, and on a variant $85 \%$ from MMC - 6,97-5,53\%, with corresponding supplies in a meter layer 950,6 and $865,8 \mathrm{~m}^{3} / \mathrm{ha}$, and in the post-reclamative period $-859,2 \mathrm{~m}^{3} / \mathrm{ha}$.
Thus, during the washing of salts from a soil profile in a cultivation period there is a decline of quantity of WM and inaccessible moisture, the interval of accessible for plants moisture increases.

The minimum moisture-capacity. As is generally known, the minimum moisture-capacity (MMC) characterizes the maximal amount of moisture, which soil can retain in itself in the suspended and equilibrium state after its abundant moistening and free flowing down of gravitational moisture. It is the most essential agronomical and soil-hydrogeological constant, on the basis of that all calculations of supplies of soil moisture, including accessible parts for the plants, washing norms, mode of irrigation and other, are conducted.

The quantity of MMC, on classification of A. Rode [10], behaves to the form of the free suspended moisture, and on availability for plants - to the category easily accessible. The minimum moisture-capacity consists of sum of firmly linked, mellow linked and capillary-suspended moisture.

After scientists' work, it was found that the quantity of MMC depends on granulometric composition, maintenance of humus, density of composition, salinization, micro and macrostructure, character of porosity of soil etc.

In the investigated soils the quantity of $\mathrm{MMC}$ before washing (1986) fluctuated in a meter layer within the limits of $23,53-22,56 \%$ from the weight of soil.

After washing there is some increase to $26,50-24,10 \%$, and after the $3^{\text {rd }}$ of cultivation of lucerne its quantity appears more higher - 27,25-25,30\%, and in a post-reclamative period (2015) in a meter layer - 27,04 - 25,91 (table - 4).

In conversion on a supply of easily accessible for the plants of MMC in a meter layer was: before washing - 3300,5, after washing - $3684,1 \mathrm{~m}^{3} / \mathrm{ha}$; after the $3^{\text {rd }}$ of cultivation of lucerne on a variant with the irrigation $75 \%$ from MMC was equal to 3741,8 on a variant $85 \%$ from MMC was equal to 3737,0 $\mathrm{m}^{3} /$ ha. After the continuous post-reclamative period reserved moistures were $3799,8 \mathrm{~m}^{3} / \mathrm{ha}$.

\begin{tabular}{|c|c|c|c|c|c|c|c|c|c|c|c|c|c|c|c|}
\hline \multirow{3}{*}{$\begin{array}{l}\text { Depth } \\
, \mathrm{cm}\end{array}$} & \multirow{2}{*}{\multicolumn{3}{|c|}{ Before washing (1986) }} & \multirow{2}{*}{\multicolumn{3}{|c|}{ After washing (1987) }} & \multicolumn{6}{|c|}{ After the three years of cultivation of lucerne (1989) } & \multirow{2}{*}{\multicolumn{3}{|c|}{ The post reclamation period }} \\
\hline & & & & & & & \multicolumn{3}{|c|}{$75 \%$ from MMC } & \multicolumn{3}{|c|}{$85 \%$ from MMC } & & & \\
\hline & MH & WM & MMC & MH & WM & MMC & MH & WM & MMC & MH & WM & MMC & MH & WM & MMC \\
\hline $0-20$ & 7,25 & 9,71 & 23,29 & 6,37 & 8,53 & 26,50 & 5,65 & 7 & 7 & 5,20 & 6,99 & 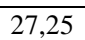 & 5,01 & 6,72 & 7,04 \\
\hline & 172,5 & 2 & 55 & $\begin{array}{c}171 \\
9\end{array}$ & 230,3 & 715,5 & $\begin{array}{c}153 \\
6\end{array}$ & $\begin{array}{c}205 \\
9\end{array}$ & 728,1 & $\begin{array}{c}136 \\
2\end{array}$ & $\begin{array}{c}7 \\
182, \\
6\end{array}$ & 9 & $\begin{array}{c}137,2 \\
5\end{array}$ & $\begin{array}{c}184,0 \\
9\end{array}$ & 0,92 \\
\hline $20-40$ & 6,35 & 8 & 2 & 5,4 & 7,3 & 25,60 & 5,24 & & 2 & 4,83 & 6,47 & & 5 , & 6,74 & 27,02 \\
\hline & 160,0 & 2 & 5 & $\begin{array}{c}151, \\
8\end{array}$ & 203,2 & 711,7 & $\begin{array}{c}144, \\
6\end{array}$ & $\begin{array}{c}193, \\
7\end{array}$ & 725,8 & $\begin{array}{c}130 \\
4\end{array}$ & $\begin{array}{c}174, \\
6\end{array}$ & 3,6 & $\begin{array}{c}137,7 \\
4\end{array}$ & $\begin{array}{c}184,6 \\
4\end{array}$ & 740,18 \\
\hline $40-60$ & 5,89 & 7,8 & 22,56 & 5,33 & 7,12 & 24,77 & 4,59 & 6,15 & 25,91 & 4,22 & 5,65 & 26,07 & 3,95 & 5,30 & 27,10 \\
\hline & 180,2 & 260,4 & 690,3 & $\begin{array}{c}156 \\
7\end{array}$ & 209,9 & 728,2 & $\begin{array}{c}130, \\
3\end{array}$ & $\begin{array}{c}174, \\
6\end{array}$ & 735,8 & $\begin{array}{c}120, \\
6\end{array}$ & $\begin{array}{c}161, \\
5\end{array}$ & 745,6 & $\begin{array}{c}108,3 \\
5\end{array}$ & $\begin{array}{c}145,2 \\
4\end{array}$ & 743,48 \\
\hline $60-80$ & 5,35 & 7,11 & 23,53 & 5,08 & 6,8 & 24,10 & 4,74 & 6,35 & 25,30 & 4,46 & 5,97 & 2 & 4,42 & 5,93 & 26,56 \\
\hline & 166,9 & 223,4 & 734,1 & $\begin{array}{c}155 \\
4\end{array}$ & 208,0 & 737,4 & $\begin{array}{c}142, \\
2\end{array}$ & $\begin{array}{c}190, \\
5\end{array}$ & 759,0 & $\begin{array}{c}132, \\
9\end{array}$ & $\begin{array}{c}177, \\
9\end{array}$ & 771,8 & $\begin{array}{c}130,1 \\
2\end{array}$ & $\begin{array}{c}174,4 \\
7\end{array}$ & 781,23 \\
\hline 80- & 4 & & 23,40 & 4,73 & 6 & 25,06 & 4,45 & 5,96 & 25 & 4,13 & 5,53 & 25 & 4,19 & 5,60 & 25,91 \\
\hline 100 & 158,7 & 212,5 & 748,8 & $\begin{array}{c}149 \\
4\end{array}$ & 200,3 & 791,9 & $\begin{array}{c}138, \\
8\end{array}$ & $\begin{array}{c}185 \\
9\end{array}$ & 793,1 & $\begin{array}{c}126 \\
4\end{array}$ & $\begin{array}{c}169, \\
2\end{array}$ & 782,1 & $\begin{array}{c}128,9 \\
5\end{array}$ & $\begin{array}{c}172,5 \\
4\end{array}$ & 794,30 \\
\hline $0-100$ & 838,3 & $\begin{array}{c}1141, \\
8\end{array}$ & $\begin{array}{c}3300, \\
5\end{array}$ & $\begin{array}{c}785, \\
2\end{array}$ & $\begin{array}{c}1051, \\
7\end{array}$ & $\begin{array}{c}3684, \\
7\end{array}$ & $\begin{array}{c}709, \\
5\end{array}$ & $\begin{array}{c}950, \\
6\end{array}$ & $\begin{array}{c}3741, \\
8\end{array}$ & $\begin{array}{c}646, \\
5\end{array}$ & $\begin{array}{c}865 \\
8\end{array}$ & $\begin{array}{c}3737, \\
0\end{array}$ & $\begin{array}{c}641,1 \\
0\end{array}$ & $\begin{array}{c}859,2 \\
2 \\
\end{array}$ & $\begin{array}{c}3799,7 \\
8\end{array}$ \\
\hline
\end{tabular}


Thus, as data shows, salinization of pratal saline lands favorably affected on the quantity of freely-accessible moisture, namely the provision of agricultural plants with accessible moisture, improves, because during the cultivation a quantity of maximal hygroscopicity reduces and MMC of soil increases and on the estimated scale of N. Kachinskiy [4] passes from unsatisfactory to satisfactory state.

\section{CONCLUSION}

After the continuous post-reclamative period (2015), in the conditions of the productive sowing some compressions of overhead horizons were occurred. The volume weight in a layer $0-100 \mathrm{~cm}$ was $1,39-1,52 \mathrm{~g} / \mathrm{cm}^{3}$.

Determination of unit weight of soil after the continuous post-reclamative period showed.

After realization of washings and cultivation of lucerne - in cultivation period (1989), and also after the continuous postreclamative period (2015) in the conditions of the productive sowing of agricultural cultures there is some decline of total porosity.

In a cultivation period - under the lucerne of $3^{\text {rd }}$ of life there is some reduction of quantity of $\mathrm{MH}$.

During the washing of salts from a soil profile in a cultivation period there is a decline of quantity of WM and inaccessible moisture, the interval of accessible for plants moisture increases.

\section{REFERENCES}

[1] L.V. Berezin, A.S. Saparov, V.M. Kang, M.R. Shayahmetov Technology for complex reclamation of Russia and Kazakhstan ecosystem, LLP "Printing and service $\mathrm{K}^{0}$ ", Almaty-Omsk.: 2013, 215p.

[2] A Saparov, Chen Shi, Zili Abduvayli. The soils of the arid zone of Kazakhstan: current state and their use, LLP "Printing and service $\mathrm{K}^{\mathrm{0}}$, Almaty, 2014, 440p.

[3] B.M. Borovsky, "Soil-reclamation conditions of irrigation development in Kazakhstan due to the transfer of the Siberian rivers" in Soil protection and rational use of land resources in Kazakhstan, B.M. Borovsky and others, Almaty: Science, 1976, pp. 78 - 85.

[4] N.A. Kaczynski. Soil Physics, Moscow: High School, Part 1, 1965, P.323.

[5] T.T. Tazabekov. "Meadow reclamation salt marshes in the area BAR", Irrigation and Water Management, vol.12, pp.21-22, 1990.

[6] Zh.U. Akhanov, V.A. Korobkin. "Changing the physical and chemical properties of gray-meadow soils Tash Utkulskogo array in the washing process", in Soil protection and rational use of land resources in Kazakhstan, Zh.U. Akhanov, V.A. Korobkin, Almaty, 1976, pp.69 - 71.

[7] B. D. Seelig, and J. L. Richardson. Salinity and sodicity in North Dakota soils. North Dakota, State Univ. Extension Service Bulletin 57, 1991.

[8] M.U. Umarov. Physical properties of soil irrigation areas of the new perspective of the Uzbek SSR, Tashkent: Fan, 1974, 282p.

[9] S.Kaldybaev Saline soils of Kazakhstan and their reclamation. Almaty: Dulat, 2014, 484p.

[10] A.A. Rode, Fundamentals of soil moisture, Leningrad: Gidrometeoizdat, 1965, 663p. 